solution of $100,000 \mathrm{ppm}$ and $10,000 \mathrm{ppm}$ were prepared. Test concentrations that were based from range finding test were prepared by pouring a specific amount of sample. Thirty mosquito larvae of fourth instar of approximately the same size were transferred into each test container. Distilled water and Malathion were used as negative and positive controls. Three trials were made using new solution and different batch of larvae. Larval mortality was recorded after $48 \mathrm{H}$ of exposure. Moribund larvae were added to the total number of dead larvae for the calculation of percentage mortality. Average larval mortality data were subjected to probit analysis and other statistics at 95 per cent fiducial limits.

Result Secondary metabolites evolved in plants protect them from herbivores due to its toxicity activity. Potential larvicidal activity of $\mathrm{CpB}$ leaf and stem extracts was noted. Ten different test concentrations were tested against mosquito larvae of fourth or fifth instar. Mean percent larval mortality of 92 was observed in the leaf extract at $10000 \mathrm{ppm}$ while 86 percent was noted in the stem extract. All plant extracts showed moderate toxic effect on mosquito larvae after 48 hours of exposure at $10000 \mathrm{ppm}$. Highest mortality was found in the leaf extract and results clearly indicate that the percentage of mortality being directly proportional to the concentration of the extracts.

Conclusion Larvicidal bioassay reveals that crude extracts possess risk to mosquito larvae at different concentrations. Leaf extract gives the higher risk to mosquito larvae.

\title{
REFERENCES
}

1 World Health Organization. Report of the WHO informal consultation on the evaluation on the testing of insecticides, CTD/WHOPES/IC/96. Geneva: WHO 1996:69.

2 Gubler DJ. Emerg Infect Dis 1998;4:442-50.

3 James AA. Science 1992:257:37-8.

4 Cagampang-Ramos A, McKenna R, Pinkovsky DD. AList of Philippine Mosquitoes Mosquito Systematics Vol 17 Philippines Department of Health. Disease Surveillance Report (2011). Dengue cases 24 September 2011, 1985.

5 Quisumbing E. Medicinal Plants of the Philippines. Katha, Caloocan City, 1978;517-8.

\section{LARVICIDAL POTENTIAL OF THE CRUDE ETHANOLIC EXTRACTS OF CENTROSEMA PUBESCENS BENTH}

Erwin Cayabyab Mina. College of Science, Tarlac State University, Tarlac City, Philippines

10.1136/bmjopen-2015-forum2015abstracts. 109

Background Mosquitoes transmit diseases and affect millions of people. Annual dengue of $36 \%$ occur in the Philippines among children aged 1-9 years. The use of medicinal herbs for curing diseases has been documented.Study assessed the antiproliferative activity of C. pubescens B. Ethanolic extract showed antibacterial and antimicrobial effect against most pathogenic organisms. Ointment of the plant showed a certain degree of wound healing activity. Evaluation of the plant with regard to its physical, biological and chemical properties that have a bearing on its successful formulation into a stable and effective pharmaceutical product be studied.

Objectives To utilize $\mathrm{CpB}$ in agrochemical industry and commercial purposes as potential larvicidal agent.

Methods Leaves and stem of $\mathrm{CpB}$ were collected, sorted, and cleaned. A voucher specimen was brought to Jose Vera Herbarium, University of the Philippines for taxonomic verification. Air-dried stems and leaves undergone extraction using 95\% ethanol filtered and concentrated in vacuo using Buchi Rotavapor. Thirty mosquito larvae were exposed to a range finding test. After determining the mortality of larvae in this range of concentrations definitive tests were conducted. Stock 